\title{
Human Vaccines for Oncogenic Viruses and Perspectives for Tumor Antigens Induced by Virus
}

\section{Giulio Tarro}

President Foundation T. \& L. de Beaumont Bonelli for cancer research, Naples, Italy

Chairman of the Committee on Biotechnologies and VirusSphere, WABT - UNESCO, Paris, France

\begin{abstract}
The Variola major, the virus that causes the smallpox, lethal virus in the $30 \%$ of the cases, was eraticated in 1979 in the human species, thanks to a capillary vaccination on global scale.

Recently the Word Health Organization (WHO) declared that India and Southeast Asia are polio-free, really a great achivement since the vaccine for polio, an infectious desease that can cause paralysis, was certificated safe and useful only 60 years ago.

The vaccine for the virus, responsible for hepatitis B infection $\mathrm{HBV}$, is able to prevent $50 \%$ of all liver cancers. Human Papilloma Virus (HPV) have been correlated with the cervical cancer (genotypes 16 and 18 particularly oncogenic in humans): the USA Food and Drug Administration (FDA) in 2006 released the first vaccine against HPV.

Finally, the ability of the immune system to recognize a tumor-associated antigen enables the development of a vaccine approach for therapeutic application and represents a main target of this field of research.

Long years of research were required for busting new systems to fight cancer. Research is going to obtain the complete sequence by proteomics approaches, in order to achieve adequate antigen preparations that might be used to generate assays for a specific anticancer vaccine.
\end{abstract}

\section{Introduction}

The purpose of this paper is to review the main historical human vaccines able to eradicate infectious diseases and then to mention the main vaccines for oncogenic viruses in man and the target given from the tumor associated antigens induced by virus for a specific anticancer vaccine.

The Variola major, the virus that causes the smallpox, lethal virus in the $30 \%$ of the cases, was eradicated in 1979 in the human species, thanks to a capillary vaccination on global scale. It has now become a "historical footprint" in two known laboratories, one in the USA and another in Russia, leaving no obvious source for its often-theorized use as a bioterrorist weapon. Nevertheless, mass vaccination against smallpox continues to be a leading initiative in Western countries to guard against bioterrorist attack [1].

There are three types of poliovirus. The type 2 Lansing and type 3 Leon have been virtually eradicated everywhere thanks to vaccines developed by Salk first in 1955 and then by Sabin in 1961 . The use of the Sabin vaccine has prevailed for the new idea to use an attenuated virus and the convenience of administration (oral and not intramuscular) and because it is cheaper. Two billions and a half among children and adults were vaccined in 200 countries, freeing up $80 \%$ of the world of this scourge and bringing down the figure of 35,000 children suffering from polio in 1988 to 279 in 2014, of which 236 cases in Pakistan. The poliovirus type 1 Brunhilde, however, has not been eradicated completely and appeared recently in Pakistan, Somalia, Ethiopia, Guinea, Kenya, and Afghanistan. Each recurrence may be the beginning of new infections, so the war can never be said completely won [2].

\section{Interaction between viruses and host}

Once entered the host cell, viruses can give rise to acute, latent or persistent infection. In the former case, the virus enters the body, replicates over a limited period of time and is then completely eliminated by the host (or causes its death). The latter types of infection are characterized by alternating replication of the virus and its latent infection, or the onset of chronic and continuous replication [3]. The site of latency is different for each subfamily of herpes viruses, but these are usually located in areas of the body where they are protected from the immune system. There are molecular mechanisms that allow the viral genome to remain in a latent state [4], and those leading to exit from latency and resumption of the lytic cycle of viral replication [5] Figure 1.

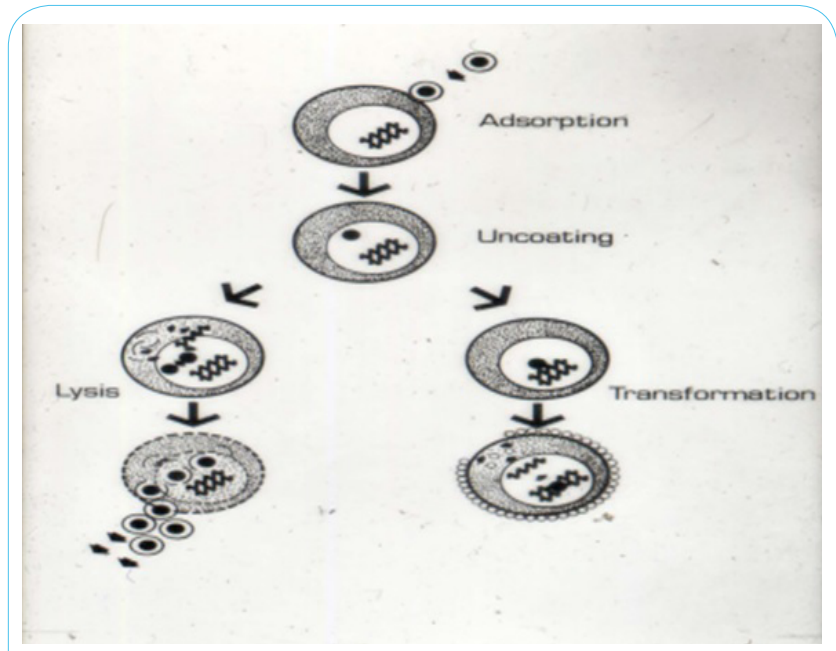

Figure 1: Interaction between DNA virus and host.

"Corresponding Author: Dr. Giulio Tarro, President Foundation T. \& L. de Beaumont Bonelli for cancer research, Naples, Italy; E-mail: giuliotarro@gmail.com

Citation: Tarro G (2016) Human Vaccines for Oncogenic Viruses and Perspectives for Tumor Antigens Induced by Virus. Int J Clin Med Microbiol 1: 114. doi: https://doi.org/10.15344/2456-4028/2016/114

Copyright: (C) 2016 Tarro. This is an open-access article distributed under the terms of the Creative Commons Attribution License, which permits unrestricted use, distribution, and reproduction in any medium, provided the original author and source are credited. 
Citation: Tarro G (2016) Human Vaccines for Oncogenic Viruses and Perspectives for Tumor Antigens Induced by Virus. Int J Clin Med Microbiol 1: 114. doi: https://doi.org/10.15344/2456-4028/2016/114

Page 2 of 6

\section{Oncogenic Viruses}

As it is known the study of the correlation between virus and tumors goes up to the beginnings of the last century when, in 1911, the American researcher Peyton Rous showed the role of the viruses to rise up some sarcoma in the chickens [3].

Today epidemiology investigations and research of laboratory have allowed to identify numerous viruses as causes of tumor. Other oncogenic viruses are : the HHV8 or herpes human virus type 8 considered the cause of the Kaposi sarcoma besides HIV (that is the so-called classical Kaposi); it is furthermore associated to various tumors, as the body-cavity-based lymphomas, the lymphoadenopaty of Castleman. The Epstain Barr virus (EBV) is considered a carcinogenic herpetic virus with conclusive evidence in the respects of the lymphoma of Burkitt, a lymphoma that often appears in immunodepressed patient, in a lymphoma of Hodgkin type $\mathrm{T}$, in the diseases of Hodgkin and in the nasopharingeal carcinoma. The HTLV1 is considered carcinogenic for the man since it causes an acute leukemia type $\mathrm{T}$ (Table 1 ) [3].

\section{- $\quad$ Proven}

Certain strains of papillomavirus (Papovaviridae)

Epstein-Barr virus (Herpesviridae)

Hepatitis B virus (Hepadnaviridae)

HTLV-I and -II (Retroviridae)

Human herpes virus-8 (Herpesviridae)

Merkel cell polyomavirus (MCV)

\section{- $\quad$ Suspect}

Hepatitis $\mathrm{C}$ virus (Flaviviridae)

Herpes simplex virus (cofactor) (Herpesviridae)

HIV-1 and -2 (Retroviridae)

Polyomavirus (BKV, JCV) (Papovaviridae)

\section{- Possible}

Adenovirus (Adenoviridae)

Table 1: Cancer Associated Viruses of Man.

Hepatitis viruses B and C are associated with hepatocellular carcinoma. Altogether, over the $50 \%$ of all liver cancer worldwide are attributable to hepatitis B infection, for which an effective preventative vaccine is available [6]. Human Papilloma Viruses (HPV) have been correlated with cervical cancer, with genotypes 16 and 18 being considered particularly carcinogenic in humans [7]. In 2006 the FDA released the first vaccine against HPV. The viral proteins E6 and E7 are able to inhibit oncosuppressors during the process of malignant transformation $[8,9]$. HCV belongs to the Flaviviridae family. Its infection can remain stable and cause mild hepatitis, liver cirrhosis or it aye volve in hepatocellular carcinoma [10]. The main strategy to evade the immune response is the genetic variation faced by the viral genome. The consequence of the heterogeneity of HCV gene expression and its ability for genetic and then phenotypic mutation, are therefore at the baseof such a high rate of chronic infections and also of the difficulty of preparing vaccines (Table 2).

Last year over 800 million doses of combination vaccines are going to be used to vaccinate Chinese children whereas more than 20 million children worldwide do not receive one or more important vaccinations that would protect them from at least one preventable disease.

\section{Cancers of Man}

- Licensed

Hepatitis B (plasma-derived and recombinant)

Adenovirus (live and killed)

Papillomavirus

- Experimental-Investigative

Retrovirus

HIV-1 and -2

AIDS

HTLV-1 and HTLV-2

Leukemia

Epstein-Barr virus

Hepatitis C

\section{Source: Modified from annals N.Y. Academy of Science}

Table 2: Examples of Licensed and Experimental Vaccines against Established or Putative Virus.

Even if there are rare cases of vaccine damage, the research to facilitate vaccination must be done to prevent diseases.

Although the threat of the infectious diseases, and therefore the problem of administering vaccinations, seem to be relatively unimportant issues in Western countries, in many areas of the 'Third World' extremely poor sanitary conditions and the unattainably high cost of vaccines could result in a death sentence for millions of people.

\section{Tumor antigens induced by virus}

Some antigens have been studied very well especially in the cellular lines and then in the newborn hamsters in which were inoculated, particularly the SV40 and the polyomavirus (Sabin and Koch) in which it has been possible not only to show the presence of the normal antigens (enzymes) of the early viral replication, but above all the socalled not structural antigens, not present in the viral particle, but present in the cells infected by the virus and in the cells transformed by the same virus, Figure 2 [3]. To these renowned antigens named type $\mathrm{T}$ (from tumor), so much have contributed the studies of the American groups lead by Huebner (NCI) and by Green (Saint Louis) for the adenoviruses, by Sabin and Tarro (Cincinnati) for some herpes

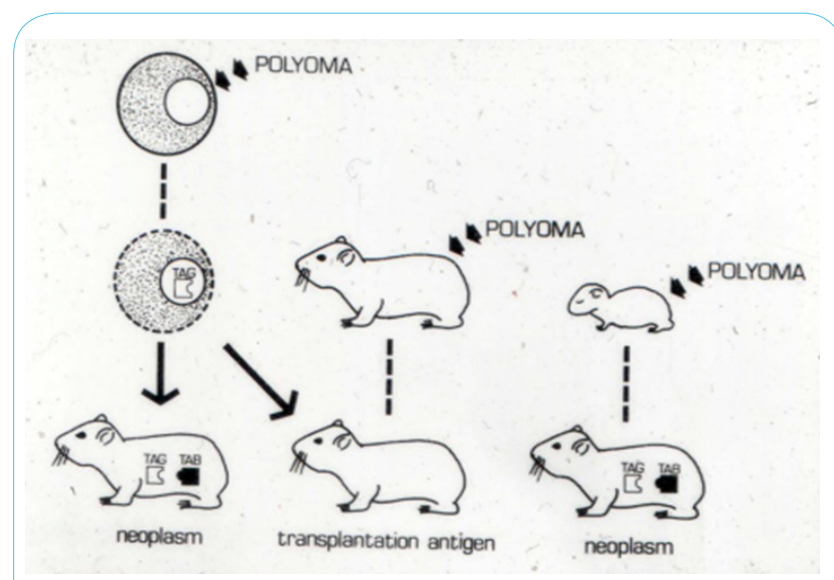

Figure 2: The polyoma virus inoculated in tissue culture (left) transforms the cells that injected into adult hamster cause cancer with production of a transplantation antigen that protects the adult animals preinoculated by the virus (middle). In newborn hamsters the polyomavirus yields straight tumors (right). 
and pox-viruses, by Melnik (Houston) for other herpes virus (VZV) and by Rapp (Hershey, Pennsylvania) for the rest of the herpetic family (CMV).

Methodologies for extracting virus and nonviral antigens, and cancer vaccine development techniques allow further steps in understanding the role of viruses and the strategies of the immune system to produce humoral and cellular antibodies. Peptide search in the tumor liberated protein and cancer proteomics represent the most advanced discovery in anticancer peptide vaccines [11].

\section{Immune response to cancer}

Long years of research were required for boosting the immune system to fight cancer.

While surgery, radiotherapy and chemotherapy are able to cure many cancers, new approaches are required to improve radical curative therapy. A possible route is to utilize the latest achievements made in research on the immunology and genetics of cancer (15). Cancer immunotherapy (19), or the manipulation of the naturally occurring oncolytic immune reaction, is based on the observation that both in animals and humans neoplastic cell antigens stimulate the onset of specific humoral and cellular antibodies (20). Certain difficulties that have been encountered reflect the lack of well-purified antigens and/ or their ability to unblock cell immunity in the cancer patient.

Two ways are known to enhance the host's immunity: aspecific activation (BCG in primis) and specific activation (to stimulate oncolytic circulating and cell antibodies). Moreover, some researchers have performed therapeutic trials with antigens, from autologous and homologous human cancer cells, obtained by various purification procedures $[12,21]$

The first observation by Tarro et al. [13] demonstrated that when TLP is extracted from a tumor, purified in the laboratory, and reintroduced into the patients body, it boosts the immune system's cancer responsive capabilities [14]. As lung cancer accounts for the largest number of cancer deaths in the Western world, TLP may have the potential to greatly improve the cure rate and/or serve as a lung cancer vaccine (Table 3) [17].

- $\quad 55 \mathrm{kd}$ protein overexpressed in lung tumors and other epithelial adenocarcinomas.

- Immunogenic in human as evidenced by serum antibodies

Table 3: TLP as a tumor - associated antigen.

\section{Chronicle of cancer immunotheraphy}

1890s - Mixtures of dead bacteria were injected by William B. Coley into cancer patients to stimulate the immune system.

1909 - According to Paul Ehrlich the immune system may suppress tumor development.

1960s - Both in animals and men neoplastic cell antigens stimulate the onset of specific humoral and cellular antibodies

1972 - Immunogenecity of a soluble transplantation antigen from adenovirus 12 - induced tumor cells demostrated in inbred hamsters (PD-4). Ariel Hollinshead et al., Can. J. Microbiol 18; 1365-1369 [12].
1975 - Discovery of Monoclonal Antibodies, highly specific immunological tools. 1980 - Mass-production of interferon, the immune-stimulating molecule, after inserting its coding gene into bacteria. Therapeutic Vaccine Strategies (A) Tumor cells are removed from a patient and treated biochemically or irradiated. Then the extracts of the dead cancer cells are reinjected, boosting the immune system to attack the tumor cell. 1983 - Tumor liberated protein (TLP) boosts the immune system's cancer responsive capabilities. G. Tarro et al., Oncology 40:248-254 [13].

1986 - Interferon is approved by the Food and Drug Administration (FDA) for the treatment of hairy cell leukemia.

1991 - TLP may have the potential to greatly improve the cure rate and/or serve as a lung cancer vaccine [14].

1997 - The FDA okays the first monoclonal antibody (MA) treatment against cancer (for non-Hodgkin's lymphoma).

1998 - The FDA approves the MA Herceptin for the treatment of metastatic breast cancer.

2002 - National Cancer Institute researchers prove that two kinds of immune cell - CD4+ T cells and CD8 $+\mathrm{T}$ cells-are required for the treatment against cancer [15].

2002 - Detection of lower levels of TLP/antiTLP may be of clinical relevance (Tarro and Esposito). TLP as candidate marker for the early detection of NSCL cancer [16].

Therapeutic Vaccine Strategies (B). Tumor - associated antigens resulting from protein bits, or from synthesized peptides specific for the cancer tissue, can be used successfully as vaccine to mount a vigorous antitumor attack.

2009 - Development of a vaccine approach for therapeutical and preventive application (Giulio Tarro, J. Cell. Physiol. 221: 26-30) [17].

Basic Cellular Immune Response to Cancer. The dendritic cell is an immune cell that presents specific antigens taken from a tumor cell to two other immune cells, the CD4+ and CD8+ cells. The CD4+ cell releases cytokine molecules that help to activate the CD8+ cells, prompting them to attack other cells with the same antigen [18].

Therapeutic Vaccine Strategies (C). The dendritic cells of a cancer patient are removed and loaded with antigens from the tumor [18]. The dendritic cells grow outside the body and then are reinjected, triggering a powerful response by the $\mathrm{T}$ cells

2010 - The FDA approves the first therapeutic cancer vaccine for advanced prostate cancer (Provenge).

\section{Materials and Methods}

According to the partial sequencing of TLP, two peptides were synthesized: TLP peptide 1: Ac-RTNKEASI-Ahx-C-amide, TLP peptide 2: Ac-Ahx-C-amide-NQRNRD

A mixing of the two peptides was administered to two rabbits in order to obtain a serum for subsequent analysis. Therefore different sera samples were taken at various dates. The capability of sera to recognize TLP was analyzed by Western blotting using protein extracts of lung cancer cell lines (A549, H23, H82, H187) and control lines (MET -SA, NL-20 and primary line of fibroblasts). The signal obtained by anti-TLP antibodies was found to be not very specific.

In order to improve the specificity of the anti- TLP antiserum a Peptide Competition Assay was carried on. In this assay, the antibody is preincubated with the peptides before its use in the immunoblotting. 
Citation: Tarro G (2016) Human Vaccines for Oncogenic Viruses and Perspectives for Tumor Antigens Induced by Virus. Int J Clin Med Microbiol 1: 114. doi: https://doi.org/10.15344/2456-4028/2016/114

Page 4 of 6

The serum obtained after purification was found to be more specific, in particular a sample specifically recognized the band of $100 \mathrm{kDa}$ and $50 \mathrm{kDa}$ protein, presumably corresponding to the TLP.

In parallel several immune precipitation assays were carried out using cell extracts of A549 and H23 lines in order to obtain a precipitate containing only the TLP protein, Figure 3.

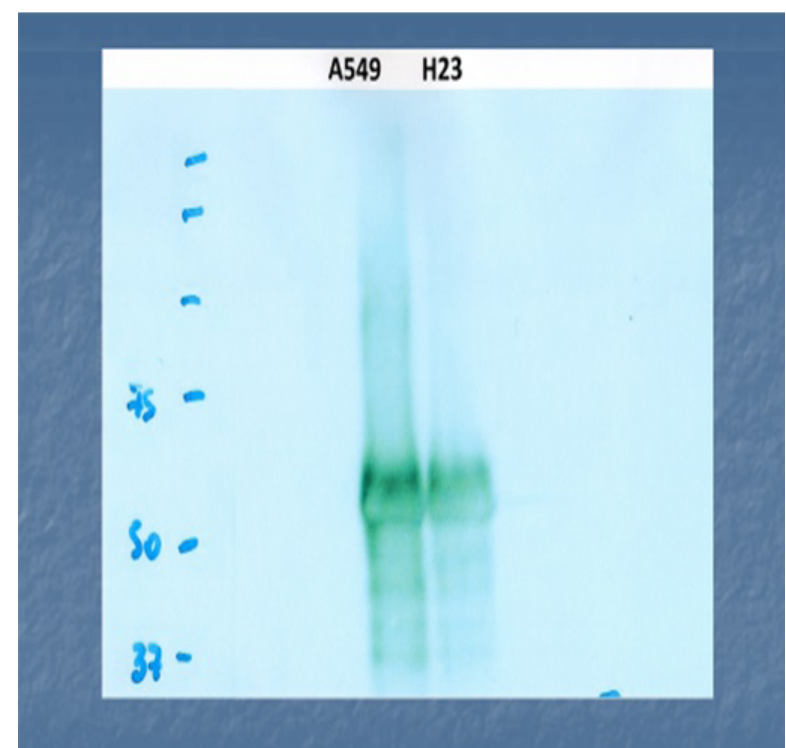

Figure 3: TLP bands by Western blot analysis from cell extracts of A549 and H23 lung cancer cell lines.

This would allow complete sequencing of the protein TLP and would also exclude the possibility that TLP and Corin are the same protein [22].

At the same time we are arranging to get a plasmid that allows us to transfect and over-express human Corin with the purpose to assess by Western blotting (with anti-TLP and anti-Corin antibodies) whether the two proteins are actually the same protein or are different.

\section{Results and Discussion}

We obtained a plasmid from Prof, Qingyu (Cleveland, Ohio) that let us transfect HEK-293 cells and overexpress the human Corin with the purpose to evaluate by Western blotting (with anti- TLP and anti-Corin) whether the two proteins are really the same protein. In parallel we are improving the tests of immunoprecipitation by the use of cell extracts derived from lung cancer cells A549 and NCI-H23 with the aim to be able of obtaining a precipitate containing only the TLP. This result would allow a better sequence of the aminoterminal fragment of TLP and furthermore would allow to look in details the homologies between TLP and Corin.

In fact the partial aminoacid sequence of TLP showes a high homology with the sequence of human Corin (at least one aminoacid is different) and is present in lung cancer under different isoforms [23]. From the references it is known that human Corin is expressed mostly outside the cells and the protein extract derived from the extracellular medium and from the cells transfected with the plasmid, which overexpresses Corin, showes many more bands analyzed on SDS-PAGE that are equivalent to the bands (about 50-100 kDa) observed in the Western blots analyzed with anti- TLP.
Tumor liberated protein (TLP), a tumor-associated antigen (complex) first described by Tarro et al., is present in the sera from lung cancer patients mainly at early stage disease. Since early detection clearly improves overall survival in lung cancer, identification of early screening biomarkers for patients at risk for the development of this disease represents an area of intense investigation.

Studies were set out to identify the nature of TLP to evaluate it further as a potential early cancer screening marker. Starting from the peptide epitope RTNKEASI, previously isolated from TLP complexes, we generated a rabbit anti-TLP serum. This antiserum detected and immunoprecipitated a $55 \mathrm{kDa}$ protein present in the supernatant as well as in the lysate of the lung cancer cell line A549. This protein was identified as aldehyde dehydrogenase isoforms $1 \mathrm{Al}$ and $3 \mathrm{~A} 1$ through mass spectrometry, reaveling the molecular nature of at least one component of the previously described TLP comlex (research ongoing at Hamburg University, personal communication).

\section{Conclusions}

\section{List of TLP functions}

TLP is a new protein extracted from tumors in vivo and transformed cells in vitro, Figure 4 [17].

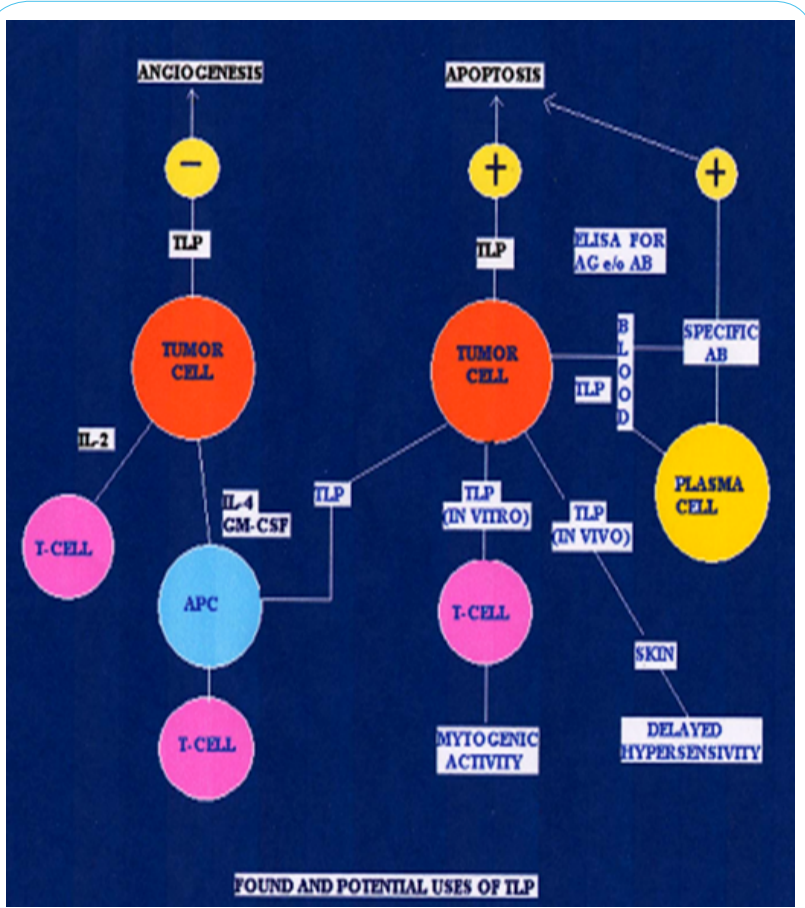

Figure 4: Observed and potential use of TLP: in vitro mytogenic activity; in vivo delayed hypersensitivity; in blood tumor liberated antigen as marker; potential induction of apoptosis; observed angiogenesis; forecast for boosting antigen presenting cells.

TLP is detectable in blood as well as in cancer tissue $[16,24]$.

TLP is a tumor associated antigen of $50 \mathrm{KD}$ monomer $[25,26]$.

TLP is overexpressed in lung tumor $[25,26]$ and other epithelial adenocarcinomas $[27,28]$. 
Citation: Tarro G (2016) Human Vaccines for Oncogenic Viruses and Perspectives for Tumor Antigens Induced by Virus. Int J Clin Med Microbiol 1: 114. doi: https://doi.org/10.15344/2456-4028/2016/114

Page 5 of 6

TLP is immunogenic in humans as evidenced by serum antibodies [29], Table 4.

\begin{tabular}{|c|c|c|}
\hline $\begin{array}{c}\text { NSCLC } \\
\text { STAGE I } \\
\text { TISSUES }\end{array}$ & POSITIVITY (\%) & NEGATIVITY (\%) \\
\hline 400 & $\begin{array}{c}56.3 \\
(225 / 400)\end{array}$ & $\begin{array}{c}43.7 \\
(175 / 400)\end{array}$ \\
\hline \multicolumn{2}{|c|}{} & NEGATIVITY (\%) \\
\hline NORMAL & POSITIVITY (\%) & \\
TISSUES & 0 & 100 \\
\hline 400 & $(0 / 400)$ & $(400 / 400)$ \\
\hline
\end{tabular}

Table 4: Sensitivity and specificity of TLP microarray.

(a) Carried out by William C. Hyun, Ph.D., at the University of California San Francisco, Cancer Center, Laboratory Cell Analysis.

Research is ongoing to obtain the complete sequence of TLP, by proteomics approaches, in order to achieve adequate antigen preparations that might be used to generate assays for early diagnosis and, possibly, a specific anticancer vaccine [30].

\section{Perspectives}

The perspectives of TLP are the following:

Since its sequences stimulate cytotoxic immunoresponse in humans and animal models, it is possible to design potential active and passive immunotherapies for NSCL cancer and colorectal cancers (CRC) based on TLP epitopes and humanized antibodies [18,31].

Fragments of TLP can be used to stimulate immune response to attack existing tumors [32].

At risk populations could be inoculated with TLP fragments to stimulate immune response to undetected or newly developing tumors $[33,34]$

Therefore the ability of the immune system to recognize TLP, represents a main target for diagnosis and therapy in this field of research.

\section{Competing Interests}

The author declares that the has no competing interests.

\section{References}

1. Tarro G (2013) Origin of the Viruses and their evolutionary History. Advanced Studies in Biology 6: 423-430.

2. Tarro G (2016) Lights and shadows of vaccination. Journal of Vaccine Research and Development 1: 1-4.

3. Tarro G (2014) Viral latency, molecular pathogenesis and malignancy. Global Journal of Sciences Frontier Research 14: 55-60.

4. Roizman B, Zhou G, Du T (2011) Checkpoints in productive and latent infections with herpes simplex virus 1: conceptualization of the issues. $J$ Neurovirol 17: 512-517.
5. Hayward GS, Donald JA, Arav-Boger R (2010) The role of KSHV in pathogenesis of Kaposi's sarcoma in Viral Oncology Khalili K., Jeang K-T. (Eds), Wiley - Blackwell, Hoboken, New Jersey, USA, 377-407.

6. Chery $\mathrm{MH}$, Chen OS (2010) Hepatitis B vaccine and hepatocellula carcinoma in Viral Oncology Kalili K., Jean K. T. (eds), Wiley- Blackwell Hoboken, New Jersy, Usa, 225-242,

7. Hausen $\mathrm{HZ}$ (2007) Infections causing human cancer. Wiley - VCH Weinheim, Germany, pp 532.

8. Baldwin A, Munger K (2010) Molecular events associated with human papillomavirus-induced human cancers in Viral Oncology Khalili K., Jeang K-T. (Eds), Wiley - Blackwell, Hoboken, New Jersey, USA, 23-55.

9. Thomas M, Pim D, Banks $L$ (2010) The role of the human papillomavirus E6 oncoprotein in malignant progression in Viral Oncology Khalili K., Jeang K-T. (Eds), Wiley - Blackwell, Hoboken, New Jersey, USA, 57-58.

10. Feitelson MA, Reis H, Pan J, Sun B (2010) Pathogenesis of acute abd chronic hepatitis $C$ virus infection in Viral Oncology Khalili K., Jeang K-T. (Eds), Wiley - Blackwell, Hoboken, New Jersey, USA, 243-266.

11. Tarro G (2013) TLP sequenced and studies for its functions with targets diagnostic and therapeutic. Advanced Studies in Biology 5: 191-198.

12. Hollinshead A, McCammon JR, Yohn DS (1975) Immunogenecity of a soluble transplantation antigen from adenovirus 12 - induced tumor cells demostrated in inbred hamsters (PD-4). Can. J. Microbiol 18:1365-1369.

13. Tarro G, Pederzini A, Flaminio G, Maturo S (1983) Human tumor antigens inducing in vivo delayed hypersensitivity and in vitro mitogenic activity. Oncology 40: 248-254.

14. Tarro G (1991) Present and future of cancer immunotherapy: Sagripanti $A$ Gagliardi C, Carpi A, Tarro G , editors. Progress in Medicine and Surgery, Proc. Nat. Meeting, San Romano (Pisa) 13 April 1991, 181-186 ETS, Publisher, Pisa.

15. Finn OJ (2008) Cancer immunology. N Engl J Med 358: 2704-2715.

16. Tarro G, Esposito C (2002) Progress and new hope in the fight against cancer: novel developments in early detection of lung cancer. Int Med 10 7-11.

17. Tarro G (2009) Tumor liberated protein from lung cancer and perspectives for immunotherapy. J Cell Physiol 221: 26-30.

18. Herberman RB (1997) Immunotherapy: where we are and how to proceed. In: Croce CM Doctor's Acta, pp 14-15.

19. Benjamini E, Rennick DM (1979) Cancer immunotherapy: facts and fancy CA Cancer J Clin 29: 362-370.

20. Weiss DW (1980) Tumor antigenicity and approaches to tumor immunotherapy. An outline. Curr Top Microbiol Immunol 89: 1-83.

21. Prager MD, Hollinshead AC, Ribble RJ, Derr I (1973) Immunity induction by multiple methods, including soluble membrane fractions to a mouse lymphoma. J Natl Cancer Inst 51: 1607.

22. $\mathrm{Wu} \mathrm{F,} \mathrm{Wu} \mathrm{Q} \mathrm{(2003)} \mathrm{Corin-mediated} \mathrm{processing} \mathrm{of} \mathrm{pro-atrial} \mathrm{natriuretic}$ peptide in human small cell lung cancer cells. Cancer Res 63: 8318-8322.

23. Qi X, Jiang J, Zhu M, Wu Q (2011) Human corin isoforms with different cytoplasmic tails that alter cell surface targeting. The Journal of Biological Chemistry 286: 20963-20969.

24. Tarro G, Perna A, Esposito C (2005) Early diagnosis of lung cancer by detection of tumor liberated protein. J Cell Physiol 203: 1-5.

25. Tarro G, Esposito C, Perna A, Claudio PP, Giordano A (1998) Immunoistochemical characterization of tumor liberated particles (TLP) expression pattern in lung cancer. Anticancer Res 18: 2365-2370.

26. Tarro G, Marshak DR, Perna A, Esposito C (1993) Antigenic regions of tumor liberated protein complexes and antibodies against the same. In: A. Carpi, A. Sagripanti, B. Grassi, editors. Third International Congress. Advances in Management of Malignancies. Pisa, Italy: 6/10 December 1993. Biomed \& Pharmacother 47: 237-240.

27. Guadagni F, Graziano P, Roselli M, Mariotti S, Bernard P, et al. (2000) Differential expression of a new tumor-associated-antigen TLP during human colorectal cancer tumorigenesis. Am J Pathol 154: 993-999.

28. Rasi G, Sinibaldi-Vallebona P, Serafino A, Bernard P, Pierimarchi P, et al (2000) A new human tumor-associated antigen (TLP) is naturally espressed in rat DHD-K12 colorectal tumor cells. Int J Cancer 85: 540-544. 
Citation: Tarro G (2016) Human Vaccines for Oncogenic Viruses and Perspectives for Tumor Antigens Induced by Virus. Int J Clin Med Microbiol 1: 114. doi: https://doi.org/10.15344/2456-4028/2016/114

Page 6 of 6

29. Esposito C, Tarro G, Cuomo N, Morelli F (1997) Anti-TLP antibodies in lung cancer patients. Int Med 5: 191-194.

30. Indovina P, Marcelli E, Maranta P, Tarro G (2011) Lung cancer proteomics: recent advances in biomarker discovery. Int J Proteomics 2011: 726869.

31. Tarro G (1999) Tumor liberated protein (TLP): its potential for diagnosis and therapy. Anticancer Res 19: 1755-1757.

32. Bernard P, Sinibaldi-Vallebona P, Rasi G, Guarino E, Guadagni F (1998) Immunisation with TLP (A new Tumor Associated Antigen) induces CTL activity in syngeneic rats. Anticancer Res 18: 4990-4994.

33. Tarro G (2000) An overview of the lung tumor liberated protein (TLP). Characterization of the genetic immunologic profile. Int Med 8: 5-8.

34. Tarro G (2002) Characterization of a fragment containing a putative TLP cDNA sequence. Anticancer Res 22: 2693-2696. 